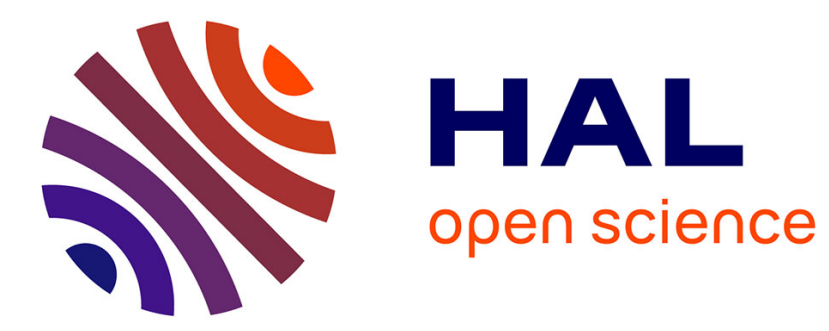

\title{
High-fiber diets in pregnant sows: digestive utilization and effects on the behavior of the animals
}

\author{
Y. Ramonet, Jean-Yves Dourmad
}

\section{To cite this version:}

Y. Ramonet, Jean-Yves Dourmad. High-fiber diets in pregnant sows: digestive utilization and effects on the behavior of the animals. Journal of Animal Science, 1999, 77, pp.591-599. hal-02684716

\section{HAL Id: hal-02684716 \\ https://hal.inrae.fr/hal-02684716}

Submitted on 1 Jun 2020

HAL is a multi-disciplinary open access archive for the deposit and dissemination of scientific research documents, whether they are published or not. The documents may come from teaching and research institutions in France or abroad, or from public or private research centers.
L'archive ouverte pluridisciplinaire $\mathbf{H A L}$, est destinée au dépôt et à la diffusion de documents scientifiques de niveau recherche, publiés ou non, émanant des établissements d'enseignement et de recherche français ou étrangers, des laboratoires publics ou privés. 


\title{
High-Fiber Diets in Pregnant Sows: Digestive Utilization and Effects on the Behavior of the Animals ${ }^{1}$
}

\author{
Y. Ramonet, M. C. Meunier-Salaün², and J. Y. Dourmad \\ I.N.R.A., Station de Recherches Porcines, 35590 Saint-Gilles, France
}

\begin{abstract}
Twelve pregnant, multiparous sows were assigned during gestation to three dietary treatments in a $3 \times 3$ Latin square design to evaluate the effect of increasing levels of crude fiber (CF ): a conventional diet low in CF $(\mathrm{L}, 15.8 \mathrm{MJ} \mathrm{DE} / \mathrm{kg}$ of $\mathrm{DM}$, $3.3 \% \mathrm{CF})$, a diet with a medium level of CF $(\mathrm{M}, 14.4$ MJ DE/kg of DM, $10.6 \% C F)$, and a high-fiber diet (H, $12.9 \mathrm{MJ} \mathrm{DE} / \mathrm{kg}$ of DM, $18.1 \% \mathrm{CF})$. The daily feed supply was adjusted to provide the same $33.4 \mathrm{MJ}$ of daily digestible energy $(2.4,2.7$, and $3.0 \mathrm{~kg} / \mathrm{d}$ for diets $L, M$, and $H$, respectively). Over the day, a shorter time standing was spent when sows received the $\mathrm{H}$ diet $(291 \mathrm{~min} / \mathrm{d})$ compared with the $\mathrm{L}(363 \mathrm{~min} / \mathrm{d})$
\end{abstract}

and $M$ diets (324 min/d). Duration of feeding was longer with the high-fiber diet. Mastication represented the main part of the feeding activity in sows fed the $\mathrm{H}$ diet (56\%) and was reduced with the $M$ and $L$ diets ( $40 \%$ and $25 \%$, respectively). Feeding rate increased when fiber level decreased $(67,120$, and $152 \mathrm{~g} / \mathrm{min}$ for the $\mathrm{H}, \mathrm{M}$, and L diets, respectively). Feeding the fibrous diet reduced the incidence of nonfeeding oral behaviors. These results show that high-fiber diets can reduce apparent feeding motivation of pregnant sows and, thus, improve the welfare of sows subjected to feed restriction.

Key Words: Sows, Nutrition, Fiber, Behavior, Animal Welfare

O1999 American Society of Animal Science. All rights reserved.

J. Anim. Sci. 1999. 77:591-599

\section{Introduction}

In practice, feeding allowance is generally restricted in pregnant sows in order to limit excessive weight gain and fat deposition, whereas they are given ad libitum access to feed during lactation (Noblet et al., 1990). During pregnancy, feed allowance has a major effect on sows' behavior. The usual feeding level represents only 50 to $60 \%$ of voluntary feed intake, inducing a sustained feeding motivation after the meal. Previous studies have shown how the inability to express this feeding motivation resulted in the development of stereotyped behavior (Rushen, 1984; Lawrence and Terlouw, 1993). Investigations have been carried out to reduce hunger and improve welfare by using higher feeding levels or providing high-fiber diets to sows housed indoors (Robert et al., 1993; Brouns et al., 1994) or outdoors (Martin and Edwards, 1994). These studies indicated potential beneficial effects of such techniques on the satiety

\footnotetext{
${ }^{1}$ This project was supported by a financial program of INRA: AIP "Aliman." The authors would like to thank V. Beaumal, S. Dubois, J . C. Hulin, M. Lefebvre, M. Massard, G. Reuzeau, and A. Roger for their technical collaboration.

${ }^{2}$ To whom correspondence should be addressed.

Received J anuary 21, 1998.

Accepted October 26, 1998.
}

level and demonstrated a reduced occurrence of stereotypies. Most of the results obtained with sows housed in stalls concerned young sows and differed in type and level of fiber. The aim of this study was to evaluate in multiparous, pregnant sows penned in stalls the effects of diets containing various fibrous components, each supplying the same daily DE.

\section{Materials and Methods}

Two successive experiments were conducted. In the first experiment, the DE and ME content of the three experimental diets were measured with growing pigs and adult sows. These diets were then used in the second experiment to evaluate their effects on pregnant sows on the basis of the same daily DE supply.

\section{Experiment 1}

Animals and Experimental Diets. The DE content of the three experimental diets was determined with six Large White nonlactating sows $(202 \pm 4.9 \mathrm{~kg} \mathrm{BW}$; mean \pm SD) and 15 Pietrain $\times$ Large White castrated males ( $54 \pm .5 \mathrm{~kg} \mathrm{BW})$. The experimental diets were formulated to provide increasing levels of crude fiber: 33,106 , or $181 \mathrm{~g} / \mathrm{kg}$ of DM in the low (L), medium ( $\mathbf{M})$, and high ( $\mathbf{H})$ diets, respectively. The $L$ diet was based on wheat, barley, and soybean meal. In the M 
and $\mathrm{H}$ diets, the wheat and soybean meal fraction was progressively replaced by a mixture of fiber-rich feedstuffs of different types (Table 1). During the digestibility trial, each sow received $2.4 \mathrm{~kg} / \mathrm{d}$ of two to three diets consecutively; each diet was evaluated with four sows. Growing pigs were fed $2.2 \mathrm{~kg} / \mathrm{d}$ of one diet only. The diets were supplied as pellets twice daily. Water was available for ad libitum consumption. Each diet was given for $21 \mathrm{~d}$, including $11 \mathrm{~d}$ for adaptation to the feed and $10 \mathrm{~d}$ in metabolism cages for total collection of feces and urine to measure the $\mathrm{DE}, \mathrm{ME}$, and digestible nutrient content of the diets.

Measurements. During each balance trial, a catheter was inserted into the bladder of sows for the $10 \mathrm{~d}$ of the collection. Urine was completely collected daily under hydrochloric acid, pooled and weighed at the end of the period, and sampled for analysis. Feces were collected daily, pooled, and, at the end of the period, weighed, mixed, subsampled, and freeze-dried for analysis. Feed and feces were analyzed for DM, ash, CP, and Weende crude fiber according to AOAC (1990). The GE content was measured with an adiabatic bomb calorimeter. Cell wall fractions (NDF, ADF, and ADL) were determined according to Van Soest et al. (1991) with previous amylolytic treatment. Nitrogen in urine was determined with fresh samples. The energy content of urine was obtained

Table 1. Composition of the experimental diets

\begin{tabular}{lccc}
\hline \hline & \multicolumn{3}{c}{ Diet $^{\mathrm{a}}$} \\
\cline { 2 - 4 } Item & $\mathrm{L}$ & $\mathrm{M}$ & $\mathrm{H}$ \\
\hline Ingredient, \% & & \\
Barley & 16.20 & 16.20 & 16.20 \\
Wheat & 65.70 & 32.85 & - \\
Soybean meal & 11.25 & 5.63 & - \\
Sunflower meal & - & 6.50 & 13.00 \\
Wheat bran & - & 6.50 & 13.00 \\
Sugar beet pulp & - & 13.00 & 26.00 \\
Soybean hulls & - & 6.50 & 13.00 \\
Corn gluten feed & - & 6.50 & 13.00 \\
Molasses & 3.00 & 3.00 & 3.00 \\
Calcium carbonate & 1.30 & .98 & .65 \\
Dicalcium phosphate & 1.10 & .90 & .70 \\
Vitamin and mineral premix & 1.00 & 1.00 & 1.00 \\
NaCl & .45 & .45 & .45 \\
Chemical analysis, \% DM & & & \\
Crude fiber & 3.30 & 10.60 & 18.14 \\
NDF & 13.51 & 25.70 & 39.43 \\
ADF & 4.32 & 12.53 & 21.16 \\
ADL & 1.12 & 2.18 & 3.73 \\
Water absorption, g H ${ }_{2} \mathrm{O} / \mathrm{g}$ DM & 1.77 & 2.99 & 3.73 \\
Gross energy, MJ /kg DM & 17.8 & 17.9 & 18.0 \\
\hline
\end{tabular}

aFiber level: low, $L$; medium, $M$; high, $H$.

${ }^{b}$ Contributed per kilogram: 10,000 IU of vitamin A; 1,500 IU of vitamin $\mathrm{D}_{3} ; 30 \mathrm{mg}$ of vitamin $\mathrm{E} ; 2 \mathrm{mg}$ of vitamin $\mathrm{K}_{3} ; 2 \mathrm{mg}$ of thiamine; $4 \mathrm{mg}$ of riboflavin; $20 \mathrm{mg}$ of niacin; $10 \mathrm{mg}$ of pantothenic acid; $3 \mathrm{mg}$ of pyridoxin; $.02 \mathrm{mg}$ of biotin; $3 \mathrm{mg}$ of folic acid; $.02 \mathrm{mg}$ of vitamin $\mathrm{B}_{12} ; 500 \mathrm{mg}$ of choline; $80 \mathrm{mg}$ of $\mathrm{Fe} ; 10 \mathrm{mg}$ of $\mathrm{Cu} ; 40 \mathrm{mg}$ of $\mathrm{Mn} ; 100 \mathrm{mg}$ of $\mathrm{Zn}$; .1 $\mathrm{mg}$ of $\mathrm{Co}$; .6 mg of I; and .15 mg of Se. after freeze drying approximately $50 \mathrm{~mL}$ in polyethylene bags. The water absorption by pellets was measured as the amount of water absorbed by $50 \mathrm{~g}$ of pellets at a temperature of $45^{\circ} \mathrm{C}$ for $30 \mathrm{~min}$. Water absorption was expressed in grams of water per gram of pellet. Apparent digestibility coefficients of energy and of the different chemical fractions were calculated according to routine procedure (Noblet and Shi, 1993).

Statistical Analysis. The model included the effect of the diet, the physiological stage (nonlactating sows or growing pigs), and the diet $\times$ physiological stage interaction. Statistical analyses were computed using the SAS GLM procedure (SAS, 1990).

\section{Experiment 2}

Animals and Experimental Procedure. Two replicates of six multiparous Large White sows were used in the behavioral experiment. Parity number of sows was $5 \pm$ .5 , and the mean live weight of the sows was $240 \pm 6$ $\mathrm{kg}$ at insemination. Three weeks after mating, the sows were moved to the experimental pens and housed individually in stalls $(.60 \times 1.90 \mathrm{~m})$ with a concrete floor and a wood shaving litter in the dunging area. Pens were cleaned daily in the morning at 1000, and fresh litter was supplied. Water was available for ad libitum consumption from a bottle calibrated for the measurement of daily water intake. Artificial lighting was provided from 0800 to 2000 and ambient temperature was kept at $18 \pm 2^{\circ} \mathrm{C}$. After $1 \mathrm{wk}$ for adaptation to the experimental room, each sow was fed the experimental diets during three successive 3-wk periods according to a $3 \times 3$ Latin square design. The diet was fed as pellets in a single meal given at 1000. On the basis of the results of the sow digestibility study, the daily feed supply was calculated to provide $33.4 \mathrm{MJ} / \mathrm{d}$ of $\mathrm{DE}(2.4,2.7$, and $3.0 \mathrm{~kg} / \mathrm{d}$ for the $\mathrm{L}, \mathrm{M}$, and $\mathrm{H}$ diets, respectively). To maintain a fixed bulk of dietary substrate and the same energy supply for the three experimental diets, wood shaving litter, which has low prehensile value and a high lignin level indigestible for pigs, was used for bedding (Chabeauti et al., 1991).

Measurements. Water and feed consumption were recorded daily throughout the experiment. At the beginning and at the end of each experimental period, sows were weighed and backfat thickness was measured at the back and neck levels using ultrasonic equipment (Sonolayer SAL-32B, Toshiba, Tokyo, J apan).

The posture of the sows was recorded at 1-min intervals using infrared barriers located at the back of the stall. Data were stored on a microcomputer. Interruption of an infrared beam was considered to be a physical activity, standing or sitting, of the animal.

Behavioral recordings were carried out by an observer between 0900 and 1500 on d 3 of wk 2 and 3 
of each period using the scan-sampling method (Altmann, 1974). The behavior was scored at 2-min intervals during the hour following the delivery of the ration (1000 to $1100, \mathrm{~h} 0$ ) and at 5 -min intervals during the other periods $(0900$ to 1000 , h $-1 ; 1100$ to 1200 , h $1 ; 1200$ to 1300 , h $2 ; 1300$ to $1400, \mathrm{~h} \mathrm{3}$; and 1400 to $1500, \mathrm{~h} 4$ ). The posture (standing, sitting, lying) and the following mutually exclusive behavioral variables were recorded for each sow: feeding, drinking, nonfeeding oral activities (Vieuille-Thomas et al., 1995), and other activities (Table 2). The nonfeeding oral activities are classically referred to as stereotyped activities (Dantzer, 1986; Lawrence and Terlouw, 1993).

During behavioral recordings, the time spent by each sow to consume the ration was measured, and the eating rate was calculated. On d 5 of wk 2 and 3 of each period, eating rate was also determined in a feeding test during which the amount of feed consumed over a 10-min period was measured.

Statistical Analysis. Values obtained with the infrared barriers corresponded to the percentage of time by minute when sows were standing. Data were averaged over 15-min periods.

The frequency of different activities performed by each sow was determined on an hourly basis and was expressed as a percentage of the total number of scans per hour.

Data were analyzed using the GLM procedure of SAS (1990) with the model for the Latin square design. Sources of variation in the full model included treatment, period, and animal. For data with repeated measurements, the effect of week of measurement was also included and the week $x$ animal interaction was used as the error term to test the effect of treatment. The week effect was not significant for any behaviors, and the values presented correspond to the average values of the 2-wk measurements. Means were separated by $\mathrm{F}$-protected LSD.

\section{Results}

\section{Experiment 1}

Addition of fibrous ingredients to the diet linearly reduced its DE and ME content for sows and growing pigs. The decrease was more marked in growing pigs than in adult sows. The DE content of the $\mathrm{H}$ diet was $25 \%$ less than that of the $L$ diet in growing pigs, whereas in sows it was only $18 \%$ less (Table 3 ). The adult sows showed a greater capacity than growing pigs to digest fibrous diets; the difference in DE content compared with growing pigs was .3, .7, and 1.2 $\mathrm{MJ} / \mathrm{kg}$ of $\mathrm{DM}$ for the $\mathrm{L}, \mathrm{M}$, and $\mathrm{H}$ diets, respectively.

\section{Experiment 2}

The analysis of the standing activity recorded with the infrared barriers showed a diurnal rhythm with two main activity periods (Figure 1 ). Whatever the experimental diet, the standing frequency peaked in the morning and started at 0700 , synchronous with light and human activity in the experimental building. During that period, animals spent more than $60 \%$ of their time standing, the highest value being at 1000 when they were fed. The amount of time sows were standing was significantly reduced at 1200 and was less than $30 \%$ of the observation time. A second period of standing activity was recorded later, between 1300 and 2000, but the values remained below $50 \%$. A significant effect of the diet was observed during these two periods of activity. The sows exhibited a lower frequency of standing posture when fed the $\mathrm{H}$ diet compared to the $L$ diet $(P<.05)$. The value obtained with the $M$ diet was intermediate and did not differ from the two other diets $(P>.05)$. Over the whole day, sows fed the $H$ diet spent less time standing (291 $\pm 110 \mathrm{~min} / \mathrm{d}$, means $\pm \mathrm{SD}$ ) than sows fed the $M$ diet $(324 \pm 140 \mathrm{~min} / \mathrm{d} ; \mathrm{P}=.001)$ or the $\mathrm{L}$ diet $(363 \pm 145$ $\mathrm{min} / \mathrm{d}$ ). However, the variation among animals was considerable; the duration of standing posture ranged from 140 to $505 \mathrm{~min} / \mathrm{d}$.

Table 2. Behavior definitions

\begin{tabular}{|c|c|c|c|}
\hline Behavior & Description & $\begin{array}{c}\text { Total } \\
\text { nonfeeding }\end{array}$ & $\begin{array}{l}\text { Total } \\
\text { oral }^{a}\end{array}$ \\
\hline \multicolumn{4}{|l|}{ F eeding activity } \\
\hline Prehension & Prehension of the feed & & $\mathrm{X}$ \\
\hline Mastication & Mastication of the feed & & $\mathrm{X}$ \\
\hline Drinking activity & & & $\mathrm{x}$ \\
\hline \multicolumn{4}{|l|}{ Oral nonfeeding } \\
\hline On the trough & $\begin{array}{l}\text { Trough licking or nosing when all the feed had been } \\
\text { consumed }\end{array}$ & $x$ & $x$ \\
\hline On bars and floor & Bar biting or licking, floor licking or rubbing & $\mathrm{X}$ & $\mathrm{X}$ \\
\hline Self-directed & Sham chew or head waving & $\mathrm{X}$ & $\mathrm{X}$ \\
\hline Lying & Recumbence, no oral activity & & \\
\hline Other activities & Activity not described above & & \\
\hline
\end{tabular}

aBehaviors summed for total nonfeeding or oral activities. 
Table 3. Energy digestibility a of the experimental diets

\begin{tabular}{|c|c|c|c|c|c|}
\hline Item & $\begin{array}{l}\text { Diet }^{\mathrm{b}:} \\
\mathrm{CF}, \% \mathrm{DM}:\end{array}$ & $\frac{\mathrm{L}}{3.30}$ & $\frac{M}{10.60}$ & $\frac{\mathrm{H}}{18.14}$ & $\mathrm{SE}^{\mathrm{C}}$ \\
\hline \multicolumn{6}{|c|}{ Apparent digestibility of energy } \\
\hline Sows & & 89.1 & 80.7 & 71.9 & - \\
\hline Growing pigs & & 87.2 & 76.6 & 65.0 & .53 \\
\hline \multicolumn{6}{|c|}{$\mathrm{DE}, \mathrm{MJ} / \mathrm{kg}$ of $\mathrm{DM}$ def } \\
\hline Sows & & 15.8 & 14.4 & 12.9 & - \\
\hline Growing pigs & & 15.5 & 13.7 & 11.7 & .09 \\
\hline \multicolumn{6}{|c|}{$M E, M J / k g$ of $D M^{\text {def }}$} \\
\hline Sows & & 15.2 & 13.6 & 12.2 & - \\
\hline Growing pigs & & 15.0 & 13.2 & 11.1 & .09 \\
\hline
\end{tabular}

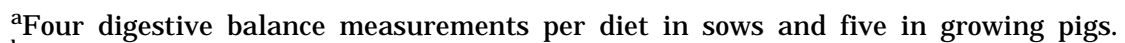

bFiber level: low, L; medium, $M$; high, $H$.

'SE $=$ Standard error.

dLinear response to dietary fiber level in sows $(P<.001)$.

e Linear response to dietary fiber level in growing pigs $(P<.001)$.

${ }^{f} E$ ffect of physiological stage $x$ diet interaction $(P<.05)$.

The analysis of the time-budget during the hour following feed delivery ( $h \quad 0$ ) showed a significant effect of fiber level on feeding and nonfeeding oral activities (Table 4), but not on drinking and lying frequency. The time devoted to feeding activity, including prehension and mastication, increased linearly with the level of fiber in the diet $(29.3,42.3$, and 76.6 for the $\mathrm{L}, \mathrm{M}$ and $\mathrm{H}$ diets, respectively; $\mathrm{P}=$ $.001)$. The frequency of prehension and mastication was significantly higher when sows were fed the $\mathrm{H}$ diet compared with the $L$ and $M$ diets. The mastication of feed represented most of the feeding activity of sows fed high-fiber diets $(25,40$, and $56 \%$ of the total feeding activity in sows fed $L, M$, and $H$ diets, respectively; $P=.001$ ). During $h 0$, the frequency of total nonfeeding oral activities, including mainly selfdirected behaviors, was significantly decreased as the fiber level increased. The frequency of total oral activities (feeding + nonfeeding + drinking) during $\mathrm{h}$ 0 was not affected by the diet $(P=.292)$. Over the whole period of behavioral recordings, the highest percentage ( $>55 \%$ ) of time spent in nonfeeding oral activities was around the meal ( $\mathrm{h}-1, \mathrm{~h} 0)$. Increasing the fibrous components in the diet significantly affected the frequency of nonfeeding oral activities at three hourly periods: before and after the meal and $3 \mathrm{~h}$ after feed distribution. In all cases, time spent in nonfeeding oral activities was shorter with the $\mathrm{H}$ diet than with the $L$ diet $(P<.001$; Table 5$)$. Before the feed distribution, the frequency of total oral activities of sows fed the $\mathrm{M}$ and $\mathrm{H}$ diets remained lower than that of sows fed the $L$ diet $(83,70$, and $62 \%$ for the $L$, $\mathrm{M}$ and $\mathrm{H}$ diets, respectively; $\mathrm{P}=.016$ ). The frequency of oral activities was positively correlated with the frequency of standing (Figure 2; $\mathrm{R}^{2}=.83 ; \mathrm{P}=.001$ ). Stage of pregnancy did not affect the frequency of oral nonfeeding activities $(P>.10)$.

The mean total feeding time was twofold and threefold higher for the $\mathrm{H}$ diet than for the $\mathrm{M}$ and $\mathrm{L}$ diets, respectively ( $P=.001$; Table 6 ). Increasing fiber level in the diet significantly decreased the feeding rate during the meal by 21 and $56 \%$ for $\mathrm{M}$ and $\mathrm{H}$ diets, respectively; the value for the $L$ diet was $152 \mathrm{~g} / \mathrm{min}$. Compared to the feeding rate measured during the meal, the feeding rate during the 10-min feeding test was higher by 21,18 , and $25 \%$ for the $L, M$, and $H$ diets, respectively.

Daily water intake was not significantly affected by the experimental diets (Table 6). Values ranged from 9 to $17 \mathrm{~L} / \mathrm{d}$, with a high variation, especially for sows fed the $L$ or $M$ diets.

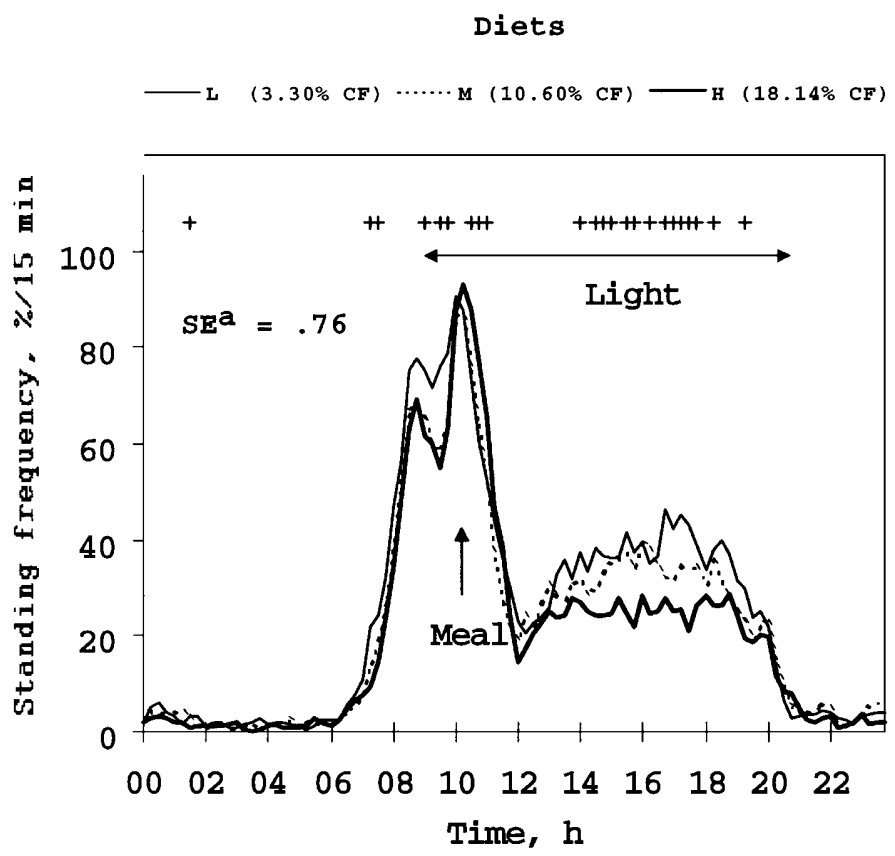

Figure 1. Standing frequency in multiparous sows according to the level of fiber in the diet (means values of the three $21-d$ periods). $+=$ effect of feed $(P<.05)$. aSE $=$ Standard error. 
Table 4. Effect of the level of fiber in the diet on the behavior of multiparous sows during pregnancy ${ }^{a}$

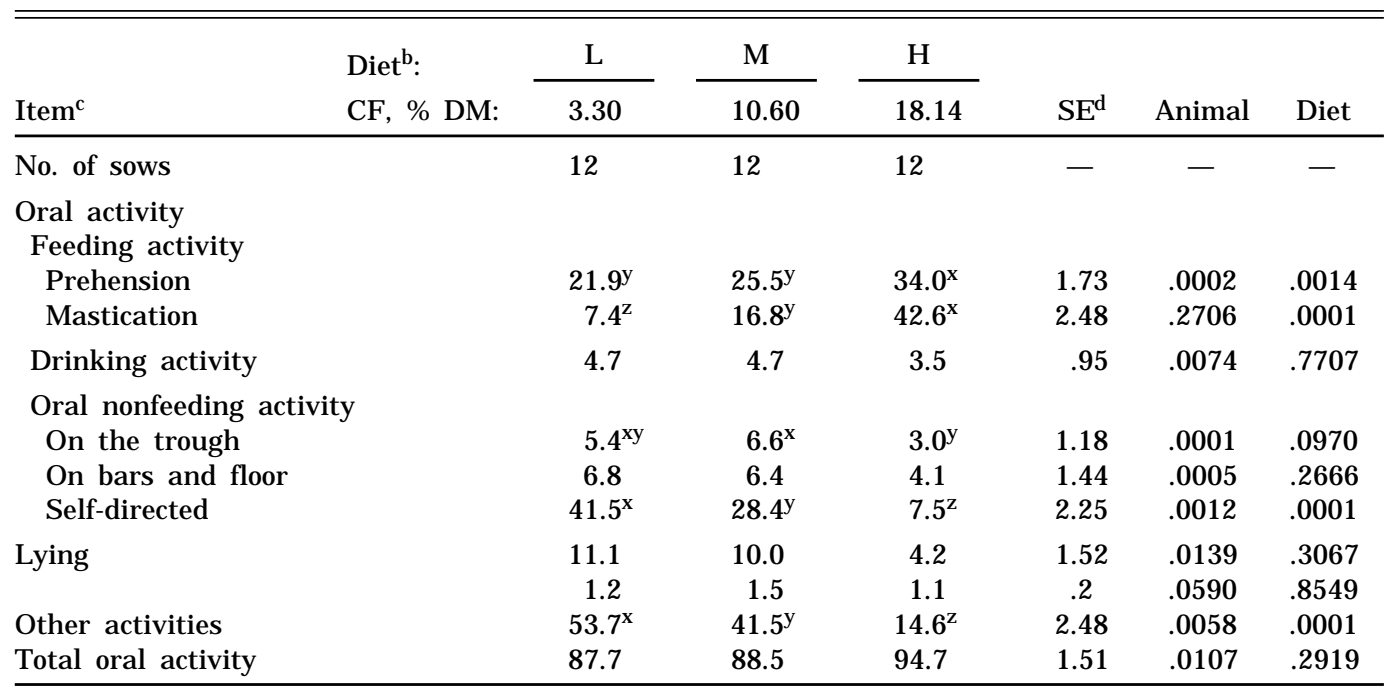

aBehavioral recordings over the hour following feed distribution; averaged adjusted-means values for the three 21-d periods.

bFiber level: low, L; medium, $M$; high, $\mathrm{H}$.

${ }^{\mathrm{C}}$ Frequency per behavior, expressed as a percentage of the total number of scans per hour.

$\mathrm{d} S \mathrm{E}=$ Standard error.

$x, y, z$ Diet effect; means with the same superscript within a row are not different $(P<.05)$.

Sows gained significantly more weight over the 21-d period when the fiber level increased (Table 7). There was no significant effect of pregnancy stage on body weight gain. Also, backfat thickness was not affected by the experimental diet.

\section{Discussion}

In agreement with Noblet and Shi (1993), the digestibility coefficient of energy in diets decreased linearly when the NDF content increased. In addition, sows showed a higher capacity to digest fibrous diets than growing pigs (Shi and Noblet, 1993). This could explain why, when DE supply is calculated based on tabulated values obtained in growing pigs, increasing the fiber content of the diet resulted in higher weight and backfat gain (Matte et al., 1994), in connection with the higher DE value of high-fiber diets for sows.

The behavioral study pointed out a nyctohemeral rhythm in standing activity. The first peak of activity can be related to feed distribution and to environmental parameters, such as light and human activity, as reported by Dourmad (1993) in lactating sows given

Table 5. Effect of the level of fiber in the diet on the occurrence of nonfeeding oral activities in multiparous, pregnant sows ${ }^{a}$

\begin{tabular}{|c|c|c|c|c|c|c|c|}
\hline Time $^{b}$ & $\begin{array}{l}\text { Dietc: } \\
\text { CF, \% DM: }\end{array}$ & $\frac{L}{3.30}$ & $\frac{M}{10.60}$ & $\frac{\mathrm{H}}{18.14}$ & $\mathrm{SE}^{\mathrm{d}}$ & Animal & Diet \\
\hline \multicolumn{2}{|c|}{ No. of sows } & 12 & 12 & 12 & - & - & - \\
\hline \multicolumn{2}{|l|}{$\mathrm{h}-1$} & $84.7^{x}$ & $68.5^{y}$ & $61.6^{y}$ & 5.08 & .0008 & .0183 \\
\hline \multicolumn{2}{|l|}{ h 0} & 53.7 & 41.4 & 14.6 & 2.51 & .0058 & .0001 \\
\hline \multicolumn{2}{|l|}{ h 1} & 53.8 & 46.4 & 40.9 & 5.63 & .0001 & .1268 \\
\hline \multicolumn{2}{|l|}{ h 2} & 35.1 & 31.1 & 21.7 & 5.37 & .0010 & .1392 \\
\hline \multicolumn{2}{|l|}{ h 3} & $34.7^{x}$ & $38.0^{x}$ & $23.2^{y}$ & 5.57 & .0001 & .0143 \\
\hline \multicolumn{2}{|l|}{ h 4} & 42.3 & 44.9 & 26.4 & 8.28 & .0026 & .2327 \\
\hline
\end{tabular}

aThe nonfeeding oral activities included the self-directed and environmentally directed behaviors; they were recorded during $6 \mathrm{~h}$ around the feed distribution. The activity is expressed as the frequency over the hourly period. Averaged adjusted values for the three $21-d$ periods.

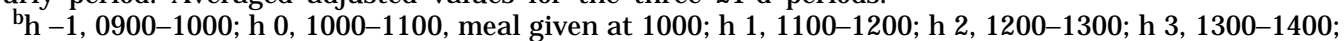

h 4, 1400-1500.

${ }^{C}$ Fiber level in diet: low, L; medium, $\mathrm{M}$; high, $\mathrm{H}$.

dSE $=$ Standard error.

$x, y, z$ Diet effects; means with the same superscript within a row are not different $(P<.05)$. 


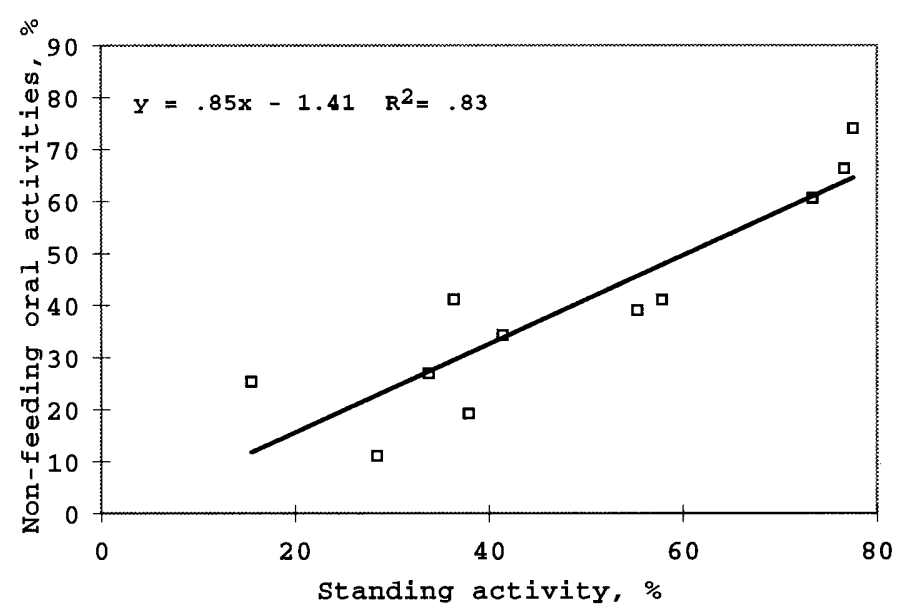

Figure 2. Average frequency of nonfeeding oral activities in multiparous sows according to the frequency of standing activity observed over $1 \mathrm{~h}$ before the meal and $4 \mathrm{~h}$ after the meal.

ad libitum access to feed. Investigations with individually confined sows fed once a day did not show a second period of activity in the afternoon (Cariolet and Dantzer, 1984; Rushen, 1985; Terlouw et al., 1991; Spoolder et al., 1995). This discrepancy could be explained by the previous experience of the sows in our study; they were fed twice a day during the previous parities.

The diet highest in fiber $(\mathrm{H})$ reduced standing activity by approximately $70 \mathrm{~min} / \mathrm{d}(25 \%)$, compared with the $\mathrm{L}$ diet, in agreement with the results obtained by Robert et al. (1993) on second-parity sows. Noblet et al. (1993) estimated that the heat production related to standing activity amounted to $14.9 \mathrm{~kJ} \cdot \mathrm{min}^{-1}$. $\mathrm{sow}^{-1}$, with a 241 -min mean duration of daily activity in their study. On this basis, the difference in the energy cost for standing activity between diets $\mathrm{L}$ and $\mathrm{H}$ would represent approximately $1 \mathrm{MJ}$ of $\mathrm{ME} / \mathrm{d}$, which corresponds to approximately $4 \%$ of the total energy requirement ( $\mathrm{N}$ oblet et al., 1990).
A positive correlation was found between standing and nonfeeding oral activities, in agreement with the observations of Cariolet and Dantzer (1984). In tethered sows, Cronin et al. (1986) reported an increase in heat production concomitant with increased stereotyped activity, which resulted in a lower retention of energy over pregnancy. This could explain the higher weight gain of the sows fed the $\mathrm{H}$ diet over the 3-wk period. However, this increased weight gain might also be related to a greater gut fill or to an increase in the development of the gastrointestinal tract in connection with the high level of fiber (Stanogias and Pearce, 1985). The higher daily supply and water-holding capacity of the high-fiber diet could also play a role in that phenomenon.

As already found by Robert et al. (1993) and Brouns et al. (1994), the occurrence of nonfeeding oral activities was reduced when sows were fed a highfiber diet. Self-directed behaviors were the main category of nonfeeding oral activities that occurred in the present study. Such behaviors have been reported to be a characteristic of high-parity sows, whereas environmentally directed behaviors are more frequent in young sows (Stolba et al., 1983). These oral activities around feeding time have been related to a persistent feeding motivation in connection with an insufficient amount of feed or energy to induce satiety and(or) with a frustration of feeding/foraging be havior (Rushen, 1985; Lawrence et al., 1988; Terlouw et al., 1991; Rushen et al., 1993). During the hour following the distribution of the meal, the effect of the high-fiber diet remained significant on nonfeeding oral activities when these behaviors were expressed according to the time available after the end of the meal. Sows masticated the high-fiber diet more than the low-fiber diet, and total oral activity (feeding + nonfeeding) was not affected by diets. These results suggest that the limited oral stimulation during the meal for sows fed the low-fiber diet would be replaced by oral behavior directed toward the environment and(or) self-directed. In feed-restricted sows, Dailey

Table 6. Effect of the level of fiber in the diet on feeding and drinking activity in multiparous, pregnant sows

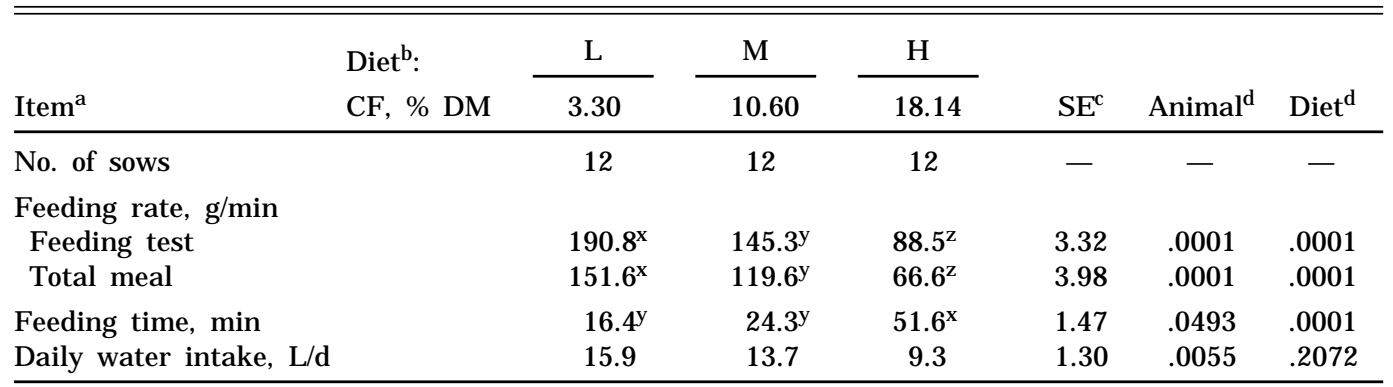

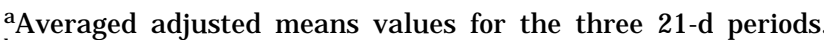

bFiber level: low, L; medium, $M$; high, $\mathrm{H}$.

'SE $=$ Standard error

$x, y, z$ Diet effect; means with the same superscript within a row are not different $(P<.05)$. 
Table 7. Effect of the level of fiber in the diet on live weight and backfat thickness in multiparous, pregnant sows

\begin{tabular}{|c|c|c|c|c|c|c|c|}
\hline & Dieta. & L & $M$ & $\mathrm{H}$ & & & \\
\hline Item & $C F, \% D M:$ & 3.30 & 10.60 & 18.14 & $\mathrm{SE}^{\mathrm{b}}$ & Animal & Diet \\
\hline No. of sows & & 12 & 12 & 12 & - & - & - \\
\hline \multicolumn{8}{|c|}{ Live weight, kg } \\
\hline Initial & & 244.7 & 242.4 & 240.5 & 2.13 & .0001 & .3989 \\
\hline Gainc & & $.2^{\mathrm{z}}$ & $7.5^{y}$ & $14.4^{x}$ & 2.22 & .7062 & .0010 \\
\hline \multicolumn{8}{|c|}{ Backfat thickness, $\mathrm{mm}$} \\
\hline Initial & & 19.4 & 19.9 & 19.6 & .25 & .0001 & .3462 \\
\hline Change $^{c}$ & & .1 & -.1 & .1 & .34 & .8206 & .8624 \\
\hline
\end{tabular}

aFiber level: low, L; medium, $\mathrm{M}$; high, $\mathrm{H}$.

bSE = Standard error.

${ }^{\mathrm{C}}$ Change over the 3-wk period.

$x, y, z$ Diet effect; means with the same superscript within a row are not different $(P<.05)$.

and McGlone (1997) found no differences in combined oral/nasal/facial frequency or duration of these behaviors between sows housed indoors and those outdoors. Redirected behaviors exhibited in a situation of thwarted motivation, such as feeding motivation during feed restriction, are often described as stereotypies, which could have a compensatory function (Dantzer, 1986). Lawrence and Terlouw (1993) suggested that feeding motivation may be channeled into oral stereotypies related partly to limited feed supply. These behaviors may be a means of maintaining feeding-related activities in the absence of sufficient incentive stimuli. Their nature depends on the available substrate for rooting or chewing, such as pen components (Rushen, 1984) and straw (Spoolder et al., 1995) or grass for sows housed outdoors (Dailey and McGlone, 1997). In the latter case, this substrate can provide a supplementary source of fiber. In our study, wood shavings were generally ignored by sows, and effects of treatment can only be attributed to the diet supplied. As pointed out by Vieuille-Thomas et al. (1995), the tendency to define oral activities as "abnormal" in a confined housing system and as more normal in a seminatural environment could be irrelevant. The cause and function of redirected oral activities are still matters for debate (Dantzer, 1986; Mason, 1991).

Generally, the nonfeeding oral activity mainly occurred in the postfeeding period (Rushen, 1985). The high frequency of oral activities observed in the present study before the feeding period could be related to the fact that the nonexperimental sows in the same building, although they were not in the same room, were fed $1 \mathrm{~h}$ earlier. Behavioral habits developed by sows during previous parities are likely to explain this discrepancy. In pregnant sows housed indoors, McGlone and Fullwood (1996) showed the effect of the rearing environment during development on the response of animals to high-fiber diets. Behavioral differences between sows fed the ex- perimental diets were still significant 4 and $23 \mathrm{~h}$ after feeding. This suggests the persistence of feeding motivation when the fiber level or the amount of feed is limited.

A high-fiber diet increased the time spent eating, in agreement with previous results (Robert et al., 1993; Brouns et al., 1994). The fiber level also affected the sows' eating rate. The sows ingested the low-fiber diet at $120 \mathrm{~g} / \mathrm{min}$, in agreement with values already reported in pregnant sows (Terlouw et al., 1991; Noblet et al., 1993; Spoolder et al., 1995). In contrast, the eating rate was lower in sows fed the $\mathrm{H}$ diet and was close to the value measured for lactating sows with ad libitum access to feed $(90 \mathrm{~g} / \mathrm{min})$ by Dourmad (1993). During the feeding test, similar differences were observed among the three experimental diets, but the values were higher whatever the diet. This result could be linked to a lower eating rate at the end of the meal, when the sows had to collect the last pellets. It could also reflect a higher feeding motivation during the initial stage of the meal, as reported by Wiepkema (1971). The eating rate remained constant over the experimental period, in contrast to results obtained by Terlouw et al. (1991) and Spoolder et al. (1995), who observed that restrictively fed gilts increased their rate of feeding between the beginning and the end of pregnancy. A strong animal effect was noted, suggesting that this criterion could reflect individual behavioral characteristics that are independent of the diet. When comparing a high level of unmolassed sugar beet diet and a barley-based diet, Brouns et al. (1997) demonstrated both immediate and long-term effects on eating speed due to organoleptic, physical, and metabolic processes during digestion. Brouns et al. (1997) suggested that a diet high in sugar beet pulp caused a rapid feeling of satiety that disappeared gradually as digestion continued. In young females aged 4 to $6 \mathrm{mo}(40$ to $60 \mathrm{~kg})$, Lepionka et al. (1997) showed a short-term effect of gastric distension on meal duration and rate of feed 
intake. Sows from the present study exhibited some difficulty in consuming the $\mathrm{H}$ diet, which was slowly masticated before ingestion, and the mastication: prehension ratio was lower when sows were fed the $L$ diet (.33) than when they were fed the $\mathrm{M}(.65)$ or $\mathrm{H}$ diet (1.25). Properties of the fibrous components such as their water-holding capacity, physical bulk, and chemical composition may be involved in this result. Thus, eating rate may not be a relevant measure of feeding motivation when the feed composition changes, as already pointed out by Martin and Edwards (1994).

The fiber level had no effect on daily water intake, although sows fed the $\mathrm{L}$ diet tended to drink more. Whatever the experimental diet, water consumption was within the range of normal values for pregnant sows: between 10 and 15 L/d (AFRC, 1990). Robert et al. (1993) obtained similar values in sows fed bulky, high-fiber diets but reported excessive drinking in sows fed a low-fiber diet (more than $25 \mathrm{~L} / \mathrm{d}$ ). Such adjunctive drinking has been related to a persistence of feeding motivation (Rushen, 1984). The lack of significant differences in the present study could be related to the large variability among individuals, especially those fed the low-fiber diet. Such variations were described in previous studies but their cause remained unclear (Madec et al., 1986; Klopfenstein et al., 1996).

In the present study, the experimental diets were formulated to provide various fibrous components, sugar beet pulp being the major one. From investigations carried out on the suitability of different fibrous ingredients in diets for sows, Brouns et al. (1995) concluded that allowing ad libitum access to a diet high in sugar beet pulp (580 to $650 \mathrm{~g} / \mathrm{kg}$ ) could give an acceptable level of energy intake without causing excessive weight gain. A beneficial effect on feeding motivation has been shown by Brouns et al. (1994) when group-housed gilts were fed $2.3 \mathrm{~kg} / \mathrm{d}$ of a diet containing a high level of sugar beet pulp ( $21 \%$ crude fiber).

\section{Implications}

Multiparous sows fed a high-fiber diet required more time to consume their daily feed ration, were quieter, and exhibited fewer nonfeeding oral be haviors. The effects appeared after the meal whatever the pregnancy stage and were more marked with a level above $12 \%$ crude fiber. Investigations over $24 \mathrm{~h}$ and for entire and successive parities are still needed. Nevertheless, fibrous diets might reduce apparent feeding motivation in restrictively fed sows. This is generally assumed to be associated with improved welfare but remains to be confirmed. Technical and environmental consequences of feeding such diets also should be evaluated.

\section{Literature Cited}

AFRC. 1990. Report number 4, Nutrient requirements of sows and boars. Nutr. Abstr. Rev. Ser. B 60:383-406.

Altmann, J. 1974. Observational study of behaviour: Sampling methods. Behaviour 49:227-267.

AOAC. 1990. Official Methods of Analysis (15th Ed.). Association of Official Analytical Chemists, Arlington, VA.

Brouns, F., S. A. Edwards, and P. R. English. 1994. Effect of dietary fiber and feeding system on activity and oral behavior of group housed gilts. Appl. Anim. Behav. Sci. 39:215-223.

Brouns, F., S. A. Edwards, and P. R. English. 1995. Influence of fibrous feed ingredients on voluntary intake of dry sows. Anim. Feed Sci. Technol. 54:301-313.

Brouns, F., S. A Edwards, and P. R. English. 1997. The effect of dietary inclusion of sugar-beet pulp on the feeding behavior of dry sows. Anim. Sci. 65:129-133.

Cariolet, R., and R. Dantzer. 1984. Motor activity of pregnant tethered sows. Ann. Rech. Vet. 15:257-261.

Chabeauti, E., J . Noblet, and B. Carré 1991. Digestion of plant cell walls from four different sources in growing pigs. Anim. Feed Sci. Technol. 32:207-213.

Cronin, G. M., J .M.F.M. van Tartwijk, W. van der Hel, and M.W.A. Verstegen. 1986. The influence of degree adaptation to tetherhousing by sows in relation to behavior and energy metabolism. Anim. Prod. 42:257-268.

Dailey, J. W., and J . J . McGlone. 1997. Oral/nasal/facial and other behaviors of sows kept individually outdoors on pasture, soil or indoors in gestation crates. Appl. Anim. Behav. Sci. 52:25-43.

Dantzer, R. 1986. Behavioral, physiological and functional aspects of stereotyped behavior: A review and a reinterpretation. J. Anim. Sci. 62:1776-1786.

Dourmad, J .-Y. 1993. Standing and feeding behavior of the lactating sow: Effect of feeding level during pregnancy. Appl. Anim. Behav. Sci. 37:311-319.

Klopfenstein, C., M. Bigras-Poulin, and G. P. Martineau. 1996. La potomanie porcine, risque zootechnique. J. Rech. Porcine Fr. 28:319-324.

Lawrence, A. B., M. C. Appleby, and H. A. MacLeod. 1988. Measuring hunger in the pig using operant conditioning: The effect of food restriction. Anim. Prod. 47:131-137.

Lawrence, A. B., and E.M.C. Terlouw. 1993. A review of behavioral factors involved in the development and continued performance of stereotypic behaviors in pigs. J. Anim. Sci. 71:2815-2825.

Lepionka, L., J. P. Laplace, and C. H. Malbert. 1997. Vagally mediated short term control of ingestion in pigs. In: J.P. Laplace, C. Février, and A. Barbeau (E d.) Digestive Physiology in Pigs. Proc. VII Int. Symp. on Digestive Physiology in Pigs. EAAP Publ. No. 88. pp 517-521. Saint-Malo, France.

Madec, F., R. Cariolet, and R. Dantzer. 1986. Relevance of some behavioral criteria concerning the sow (motor activity and water intake) in intensive pig farming and veterinary practice. Ann. Rech. Vet. 17:177-184.

Martin, J . E., and S. A. Edwards. 1994. Feeding behavior of outdoor sows: the effect of diet quantity and type. Appl. Anim. Behav. Sci. 41:63-74.

Mason, G. J . 1991. Stereotypies: A critical review. Anim. Behav. 41: 1015-1037.

Matte, J . J ., S. Robert, C. L. Girard, C. Farmer, and G.-P. Martineau. 1994. Effect of bulky diets based on wheat bran or oat hulls on reproductive performance of sows during their first two parities. J. Anim. Sci. 72:1754-1760.

McGlone, J . J ., and S. D. Fullwood. 1996. Stereotyped oral/nasal/ facial behaviors, reproduction and immunity of crated sows: Effects of high dietary fiber and rearing environment. J . Anim. Sci. 74(Suppl. 1):131 (Abstr.).

Noblet, J ., J .-Y. Dourmad, and M. Etienne. 1990. Energy utilization in pregnant and lactating sows: Modeling of energy requirements. J. Anim. Sci. 68:562-572. 
Noblet, J., and X. S. Shi. 1993. Comparative digestibility of energy and nutrients in growing pigs fed ad libitum and adults sows fed at maintenance. Livest. Prod. Sci. 34:137-152.

Noblet, J ., X. S. Shi, and S. Dubois. 1993. Energy cost of standing activity in sows. Livest. Prod. Sci. 34:127-136.

Robert, S., J . J. Matte, C. Farmer, C. L. Girard, and G.-P. Martineau. 1993. High-fiber diets for sows: Effects on stereotypies and adjunctive drinking. Appl. Anim. Behav. Sci. 37:297-309.

Rushen, J . 1984. Stereotyped behavior, adjunctive drinking and the feeding periods of tethered sows. Anim. Behav. 32:1059-1067.

Rushen, J. P. 1985. Stereotypies, aggression and the feeding schedules of tethered sows. Appl. Anim. Behav. Sci. 14:137-147.

Rushen, J ., A. B. Lawrence, and E.M.C. Terlouw. 1993. The motivational basis of stereotypies. In: A. B. Lawrence and J. Rushen (Ed.) Stereotypic Animal Behavior: Fundamentals and Applications to Welfare. pp 41-64. CAB International, Wallingford, U.K.

SAS. 1990. SAS/STAT ${ }^{\circledR}$ User's Guide (Version 6, 4th E d.). SAS Inst. Inc., Cary, NC.

Shi, X. S., and J. Noblet. 1993. Contribution of the hindgut to digestion of diets in growing pigs and adult sows: Effect of diet composition. Livest. Prod. Sci. 34:237-252.

Spoolder, H.A.M., J. A. Burbidge, S. A. Edwards, P. H. Simmins, and A. B. Lawrence. 1995. Provision of straw as a foraging substrate reduces the development of excessive chain and bar manipulation in food restricted sows. Appl. Anim. Behav. Sci. 43:249-262.

Stanogias, G., and G. R. Pearce. 1985. The digestion of fiber by pigs. 1. The effects of amount and type of fiber on apparent digestibility, nitrogen balance and rate of passage. Br. J. Nutr. 53: 513-530.

Stolba, A., N. Baker, and D.G.M. Wood-Gush. 1983. The characterisation of stereotyped behavior in stalled sows by informational redundancy. Behaviour 87:157-182.

Terlouw, E.M.C., A. B. Lawrence, and A. W. Illius. 1991. Influences of feeding level and physical restriction on development of stereotypies in sows. Anim. Behav. 42:981-991.

Van Soest, P. J ., J . B. Robertson, and B. A. Lewis. 1991. Methods for dietary fiber, neutral detergent fiber, and nonstarch polysaccharides in relation to animal nutrition. J. Dairy Sci. 74: 3583-3597.

Vieuille-Thomas, C., G. Le Pape, and J. P. Signoret. 1995. Stereotypies in pregnant sows: Indications of influence of the housing system on the patterns expressed by the animals. Appl. Anim. Behav. Sci. 44:19-27.

Wiepkema, P. R. 1971. Positive feed-backs at work during feeding. Behaviour 39:266-273. 